\title{
Microencapsulation of pumpkin seed oil by spray dryer under various process conditions and determination of the optimal point by RSM
}

\section{Geranpour, M. ${ }^{\text {a* }}$; Emam-Djomeh, Z. ${ }^{\text {b; Asadi, G. }}{ }^{\text {a }}$}

a Department of Food Science and Technology, Science and Research Branch, Islamic Azad University, Tehran, Iran.

b Transfer Phenomena Laboratory (TPL), Department of Food Science, Technology and Engineering, University of Tehran, Iran.

*E-mail of the corresponding author: m.geranpour@yahoo.com

\begin{abstract}
The objective of this research was to microencapsulating the pumpkin seed oil (PSO) by the spray dryer and also investigating the effects of some process conditions on physicochemical properties of PSO microparticles. Inlet drying air temperature (140-180 C), aspirator rate (55-75\%), and peristaltic pump rate (5-15\%) effects were studied. Moisture content (\%W.b.), Microencapsulation Efficiency (MEE, \%) and Peroxide value (POV, meq $/ \mathrm{kg}$ sample) considered as model responses. Consequently, the ideal drying state for microencapsulation of PSO as a result of optimizing by Response Surface Methodology (RSM) determined with the aim of minimizing the Moisture content and POV and maximizing the MEE.
\end{abstract}

Keywords: Microencapsulation; spray dryer; pumpkin seed oil; optimization; RSM. 


\section{Introduction}

pumpkin (Cucurbita pepo.) seed oil is a functional food and comprises various bioactive components such as vitamins[1], poly and monounsaturated fatty acids, proteins and minerals[2,3]. The major part of fatty acids of pumpkin seed oil (PSO) is linoleic acids (Omega-6 fatty acids) which is one of the most beneficial substances for human health[2]. Moreover, it has positive effects such as having anti-inflammatory and diuretic properties[4], decreasing total and LDL cholesterol levels, improving treatment of benign prostate hyperplasia[4], relieving diabetes by improving hypoglycemic activity[5], etc. In addition, utilization of PSO from pumpkin seeds as agro-industrial wastes, reduce the growth of environmental problems[6]. Microencapsulation is considered as an approach, which protects bioactive compounds, improves their stability and even can mask the unpleasant feelings during eating[7]. This process incorporates food ingredients in small capsules that may range from micrometer to millimeter in size and may have different shapes[8]. Among the numerous developed microencapsulation techniques, spray drying is the oldest and most widely used procedure in food industrial sector due to providing highquality products[9]. Therefore the aim of this study was to investigate the process conditions as independent variables on dependent variables and suggest the optimal point for producing the PSO microencapsulated powder.

\section{Materials and Methods}

\subsection{Materials}

Pure PSO (Cucurbita pepo species, Styarica variety) was purchased after cold pressed process from Zardband Co.(Tehran, Iran). The used wall materials were gum Arabic (GA), maltodextrin DE-6 (MD), and whey protein concentrate (WPC) with 80\% protein supplied by Merck Co.(Darmstadt, Germany), Roquette Co.(Lestrem, France), and Hilmar Ingredients Co.(California, USA), respectively.

\subsection{Emulsion preparation}

The ratio of $10 \%$ core material, $20 \%$ wall material, and $70 \%$ water was used to prepare the emulsion[10]. Utilizing the formulation of $17 \%$ GA, 17\% WPC, and 66\% MD, wall materials were dissolved in distilled water one day before emulsification to access complete hydration. PSO was gradually added to the barricade material solution and homogenized at $1000 \mathrm{rpm}$ for 5 min using a rotor-stator homogenizer (Ultraturrax Ika T25, Deutschland, Germany) at ambient temperature[11].

\subsection{Drying apparatus and Microencapsulation of PSO}

laboratory scale dryer (BÜCHI Mini spray dryer B-191, Flawil, Switzerland) equipped with a two-fluid internal mixing nozzle atomizer with $0.7 \mathrm{~mm}$ diameter used. Before each 
experiment, the dryer run with distilled water about 15 minutes to achieve the steady-state condition. The spray drying conditions examined in this study were inlet drying air temperature (140-180 C), aspirator rate (55-75\%), and peristaltic pump rate (5-15\%).

\subsection{Analysis of microparticles}

\subsubsection{Moisture content}

Moisture content was determined by drying 2 grams of powders at $70{ }^{\circ} \mathrm{C}$ to constant weight (24 hours) in the oven according to AOAC method (1984) and reported as \%W.b[12].

\subsubsection{Microencapsulation efficiency}

Microencapsulation efficiency (MEE) was measured based on the method described by Bae and Lee[13]. Surface oil was measured by extraction with hexane. According to preliminary tests, PSO is not volatile oil. Thus, total oil weight was assumed to be equal to the initial oil. Consequently, MEE was calculated using the following equation:

$$
\text { MEE }=\frac{\text { Total oil__Surface oil }}{\text { Total oil }} \times 100
$$

\subsubsection{Peroxide value}

The POV was denoted after 3 months according to ISO 3976/IDF standard 74:2006 method[14], which is based on the co-oxidation of Fe (II) to Fe (III) and formation of the reddish Fe (III)-thiocyanate complex. The absorbance of the samples was read at $500 \mathrm{~nm}$ by a spectrophotometer against the blank solution [15]. Finally, the following equations were used to calculate the POV[14]:

$$
\begin{aligned}
& \mathrm{POV}=\frac{0.5 \mathrm{mc}}{55.84 \mathrm{~m}} \\
& \mathrm{mc}=\frac{\mathrm{E}}{\mathrm{b}}
\end{aligned}
$$

where $\mathrm{m}$ is the fat weight expressed as $\mathrm{g}, 55.84$ is the atomic weight of Fe3+, $\mathrm{E}$ is the absorbance of the sample determined using a spectrophotometer, and b is the slope of the Fe (III) calibration curve obtained as 0.0276 from its standard plot.

\subsubsection{Experimental design}

The response surface methodology (RSM) was utilized to investigate the effects of process conditions on dependent variables, and also optimization. For this purpose, the DesignExpert software (State Ease Inc., Minneapolis, USA), version 11 was used and 17 random 
Microencapsulation of pumpkin seed oil by spray dryer under various process conditions and determination of the optimal point by RSM

runs in 5 central points were designed by Box-Behnken experimental design (BBD) in a full factorial plan. All data in this study were reported as averages of triplicate experiments.

\section{Results and Discussion}

The results of ANOVA and regression coefficients for the model by eradicating the nonsignificant terms of responses are listed in Table 1.

Table 1. ANOVA results and regression coefficients for responses surface quadratic model.

\begin{tabular}{|c|c|c|c|c|c|c|c|c|c|c|}
\hline \multirow[t]{2}{*}{ Source } & \multirow[t]{2}{*}{$\begin{array}{l}\mathbf{D} \\
\mathbf{F}\end{array}$} & \multicolumn{3}{|c|}{ Moisture content (\%W.b.) } & \multicolumn{3}{|c|}{ MEE (\%) } & \multicolumn{3}{|c|}{$\begin{array}{c}\text { POV in month } 3 \\
\text { (meq.pov/1kg sample) }\end{array}$} \\
\hline & & $\begin{array}{c}\text { COEF } \\
F \\
\end{array}$ & SS & $\begin{array}{c}\text { P- } \\
\text { Value }\end{array}$ & $\underset{\text { COEF }}{\text { F }}$ & SS & P-Value & $\begin{array}{c}\text { COE } \\
\text { FF }\end{array}$ & SS & $\begin{array}{c}\mathbf{P}- \\
\text { Value }\end{array}$ \\
\hline Model & & 3.18 & 7.96 & $\begin{array}{c}0.0177 \\
*\end{array}$ & 78.54 & 267.74 & $0.0219 *$ & $\begin{array}{c}16.9 \\
8\end{array}$ & 90.55 & $0.0002 *$ \\
\hline linear & & & & & & & & & & \\
\hline$b_{1}$ & 1 & -0.23 & 0.44 & 0.1441 & 0.029 & 0.0066 & 0.9742 & 0.25 & 0.51 & 0.3008 \\
\hline$b_{2}$ & 1 & -0.18 & 0.25 & 0.2549 & 2.82 & 63.51 & $0.0133^{*}$ & -1.37 & 14.99 & $0.0005^{*}$ \\
\hline $\begin{array}{l}\mathrm{b}_{3} \\
\text { quadratic }\end{array}$ & 1 & 0.41 & 1.33 & $0.024^{*}$ & 2.18 & 38.15 & $0.0382 *$ & 1.72 & 23.77 & $0.0001^{*}$ \\
\hline $\mathrm{b}_{11}$ & 1 & -0.25 & 0.27 & 0.2397 & -1.54 & 9.96 & 0.2341 & -0.6 & 1.52 & 0.095 \\
\hline$b_{22}$ & 1 & -0.49 & 0.99 & $\begin{array}{c}0.0427 \\
*\end{array}$ & 3.07 & 39.8 & $0.0353^{*}$ & -0.26 & 0.29 & 0.4255 \\
\hline$b_{33}$ & 1 & -0.78 & 2.54 & $\begin{array}{l}0.0054 \\
*\end{array}$ & 4.2 & 74.34 & $0.0093^{*}$ & 1.03 & 4.49 & $0.0128 *$ \\
\hline $\begin{array}{l}\text { interaction } \\
\mathrm{b}_{12}\end{array}$ & 1 & 0.44 & 0.78 & 0.0636 & -0.24 & 0.23 & 0.8502 & 2.6 & 27.03 & $<0.0001^{*}$ \\
\hline $\mathrm{b}_{13}$ & 1 & -0.5 & 1.02 & $\begin{array}{c}0.0401 \\
*\end{array}$ & 0.34 & 0.45 & 0.7902 & 1.11 & 4.91 & $0.0104 *$ \\
\hline $\mathrm{b}_{23}$ & 1 & 0.075 & 0.023 & 0.7201 & -3.15 & 39.75 & $0.0354 *$ & -1.83 & 13.34 & $0.0007 *$ \\
\hline Residual & 7 & & 1.13 & & & 41.12 & & & 2.85 & \\
\hline Pure error & 4 & & 0.0029 & & & 7.98 & & & 0.0019 & \\
\hline $\mathrm{R}^{2}$ & & 0.87 & & & 0.86 & & & 0.96 & & \\
\hline Adj-R $R^{2}$ & & 0.71 & & & 0.69 & & & 0.93 & & \\
\hline CV (\%) & & 16.36 & & & 2.98 & & & 3.74 & & \\
\hline $\begin{array}{l}\text { Adequate } \\
\text { precision }\end{array}$ & & 6.63 & & & 6.78 & & & $\begin{array}{c}22.0 \\
1\end{array}$ & & \\
\hline
\end{tabular}

*: significant effect at level $\mathrm{p}<0.05$

The significance of all terms was expressed at a probability (P) level of 0.05 . The results showed that the suggested model was quadratic for the whole responses.The following mathematical equation was fitted to data:

$y=\beta_{0}+\beta_{1} X_{1}+\beta_{2} X_{2}+\beta_{3} X_{3}+\beta_{11} X_{1}^{2}+\beta_{22} X_{2}^{2}+\beta_{33} X_{3}^{2}+\beta_{12} X_{1} X_{2}+\beta_{13} X_{1} X_{3}+\beta_{23} X_{2} X_{3}+\varepsilon$

where $\beta n$ are constant regression coefficients, $y$ is the predicted response (Moisture content, MEE and POV), and $X 1, X 2$, and $X 3$ are the coded independent variables.

\subsection{Moisture content}

Moisture content varied between 1.19\% and 3.35\% wet basis. Peristaltic pump rate had the most significant effect $(\mathrm{P}<0.05)$ on the MEE (Fig. 1a). As the inlet air temperature increased, the drying chamber temperature increased, which caused a decrease in the 
moisture content. By raising aspirator rate, the supplied energy in the drying chamber increased and the moisture of droplets in the chamber evaporated more easily. At high peristaltic pump rates and subsequently high atomized emulsion in the drying chamber, the contact time of droplets with the hot drying air reduced; hence, their interior evaporation retarded. This procedure resulted in the generation of microcapsules with high moisture content at high feed flow rates. Similar results were reported by Goula et al.[16], Aghbashlo et al.[10], and Muzaffar and Kumar[17] about the effect of inlet air temperature, aspirator rate and peristaltic pump rate on spray drying, respectively. Fig. 1b shows the levels of inlet air temperature and peristaltic pump rate on moisture content.

a

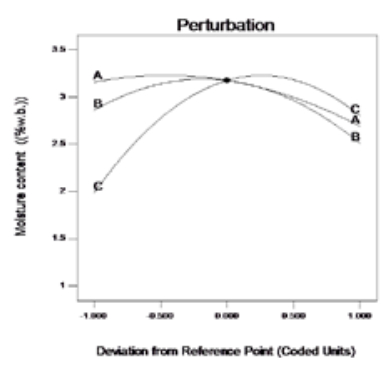

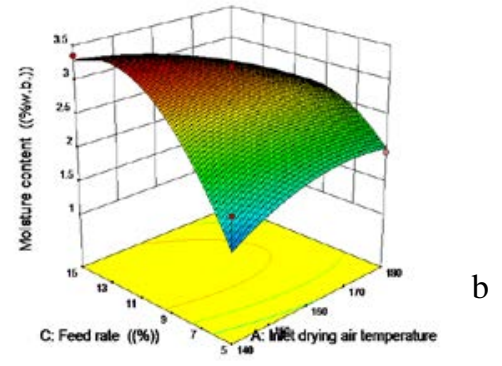

b

Fig.1. Effect of variables on moisture content(a), 3D response surface plot for moisture content (b).

\subsection{Microencapsulation efficiency}

The MEE varied from a minimum value of $75.36 \%$ to a maximum value of $90.95 \%$. As demonstrated in Fig. 2a, increasing both aspirator rate and peristaltic pump rate directly affected and increased MEE. Fig. 2b shows the 3D surface response for MEE.

a

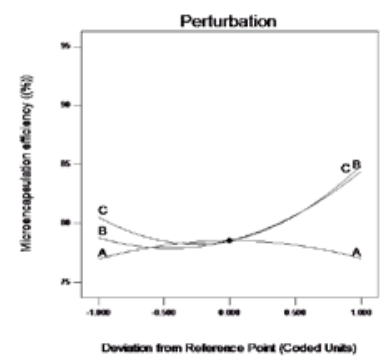

Fig. 2.

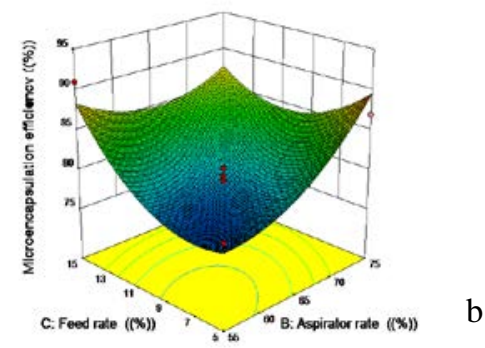

Effect of independent variables on $\mathrm{MEE}$ (a), 3D response surface plot for $M E E(b)$.

The fast formation of crust at early stages as a result of enhancing aspirator rate plays a vital role in generating particles with high MEE[18]. This acceleration in crust formation diminished diffusion of oil to the surface of microcapsules and consequently increased MEE. This was similar to the explanation of Aghbashlo et al in 2012[10]. The higher velocity of feed flow rate resulted in producing smaller particles during the drying process. 
Break of the particles as the result of their collision with each other in the drying chamber was the main reason for this phenomenon[19], which hastened the crust layer formation. Moreover, it reduced the amount of surface oil and correspondingly enhanced MEE.

\subsection{Peroxide value}

After 3 months, the POV of the produced PSO microcapsules was found to be between 12.11 and $23.08 \mathrm{meq} / \mathrm{kg}$. Inlet air temperature was an ineffective parameter in altering the POV ( $>$ > 0.05; Fig. 3a). The 3D response surfaces for powder POV are illustrated in Fig. 3b, 3c, and 3d. As discussed earlier, increased aspirator rate increased the MEE (Fig. 2a) and led to high oil protection against oxidation and resulted in the reduction of POV (Fig. 3a). The presence of produced particles with high POV at high ranges of feed flow rate probably might be attributed to the chemical and physical changes taking place in the formation of the capsule walls. The higher the accumulated droplets in the drying chamber as a result of increasing the feed flow rate, the lower was the time spent for drying, which led to the appearance of the crust with insufficient solidity on the outer layer of particles. Aghbashlo et al.[10] reported similar results for POV, which was influenced by feed flow rate.

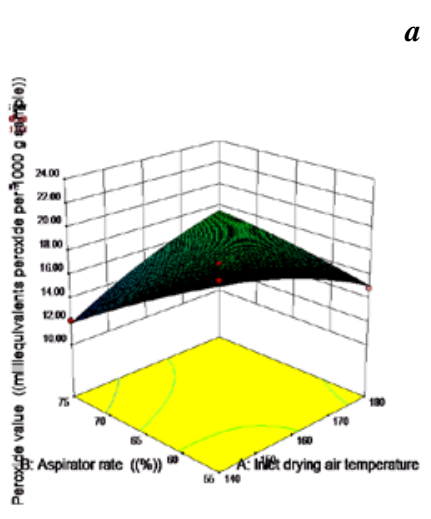

b
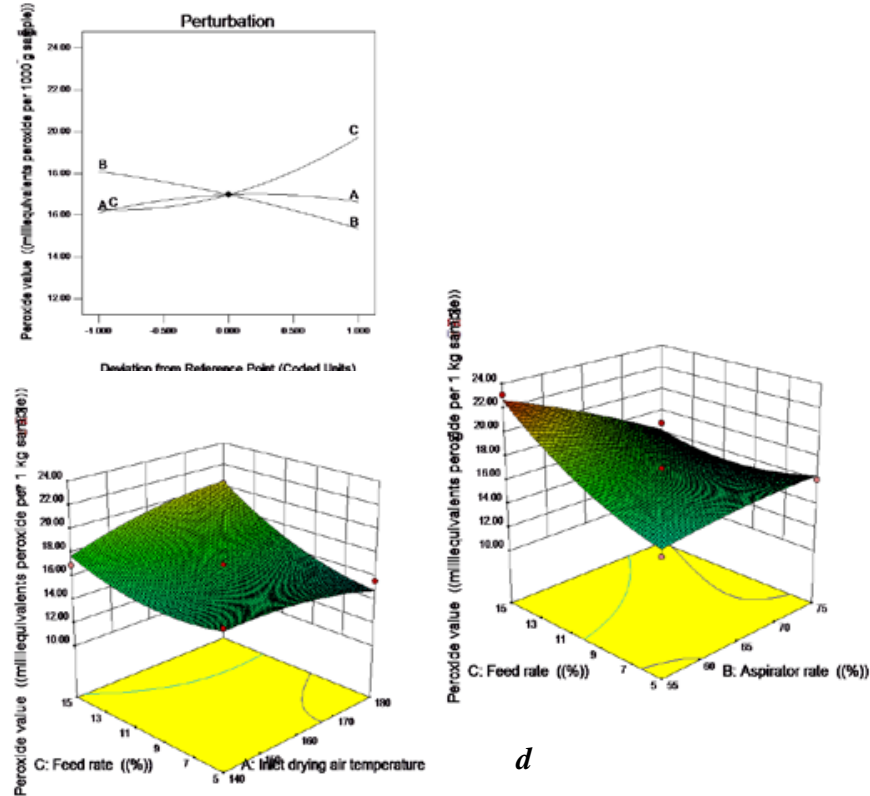

$d$

Fig. 3. Effect of independent variables on POV(a), 3D response surface plots for POV (b,c, and d.).

The maximum and the minimum determined POV after 3 months was $23.08 \mathrm{meq} / \mathrm{kg}$ and $12.11 \mathrm{meq} / \mathrm{kg}$, respectively. The microencapsulated powder was produced again under process conditions which the mentioned POV was determined, and the POV measured immediately were 9.03 and $6.93 \mathrm{meq} / \mathrm{kg}$, respectively. Comparing these amounts of POV before and after the passage of the time represented that microencapsulation by a spray 
dryer, could protect the PSO against the huge amount of lipid oxidation, which might occur for the un-encapsulated oil after three months.

\subsection{Optimization}

In order to achieve the best conditions for a process, optimization which is an essential tool to obtain acceptable results from various processes, used. As the higher amounts of MEE and lower amounts of POV lead to lower deterioration of pumpkin seed oil by oxygen and lengthened storage time of the product[10], optimization performed to minimizing the Moisture content as a characteristic of the drying process, maximizing the MEE and minimizing the POV. Consequently, the ideal drying state for microencapsulation of PSO was suggested by RSM to be inlet air temperature of $140{ }^{\circ} \mathrm{C}$, aspirator rate of $75 \%$, and peristaltic pump rate of $5 \%$ to offer moisture content of 0.27 (\%W.b.), microencapsulation efficiency of $88.60 \%$, and peroxide value of $13.97 \mathrm{meq} / \mathrm{kg}$ sample with the total desirability of $89 \%$.

\section{Conclusion}

The research indicates that spray drying is the suitable method to obtain the high amount of MEE in microencapsulating of PSO under the studied process conditions. Spray drying conditions such as aspirator rate and peristaltic pump rate significantly affected the characteristics of PSO microcapsules. Inlet air temperature had no significant effect on alteration of output responses, which could be related to its low range of variation (140 $180^{\circ} \mathrm{C}$ ).Microencapsulation by a spray dryer could protect the PSO against the high amount of lipid oxidation according to POV analysis.

\section{References}

[1] Stevenson, D. G., Eller, F. J., Wang, L., Jane, J. L., Wang, T. and Inglett, G. E. Oil and tocopherol content and composition of pumpkin seed oil in 12 cultivars. Journal of Agricultural and Food Chemistry. 2007, 55(10), 4005-4013.

[2] Xanthopoulou, M.N., Nomikos,T., Fragopoulou,E., Antonopoulou, S. Antioxidant and lipoxygenase inhibitory activities of pumpkin seed extracts. Food research international. 2009, 42, 641-646.

[3] Gohari Ardabili, A., Farhoosh, R., and Haddad Khodaparast, M. H. Chemical composition and physicochemical properties of pumpkin seeds (Cucurbita pepo Subsp. pepo Var. Styriaka) Grown in Iran. Journal of Agricultural Science and Technology. 2011, 13, 1053-1063.

[4] Fruhwirth, G. O., \& Hermetter, A. Seeds and oil of the Styrian oil pumpkin: Components and biological activities. European Journal of Lipid Science and Technology. 2007, 109(11), 1128-1140.

[5] Fu, C., Shi, H., Li, Q. A review on pharmacological activities and utilization technologies of pumpkin. Plant Foods for Human Nutrition. 2006, 61(2), 73-80. 
[6] Da silva, A. C. and Jorge, N. Bioactive compounds of the lipid fractions of agroindustrial waste. Food Research International. 2014, 66(1), 493- 500.

[7] Nedovic, V., Kalusevic, A., Manojlovic, V., Levic, S., \& Bugarski, B. An overview of encapsulation technologies for food applications. procedia Food Science. 2011, 1 (1), 1806-1815.

[8] Aberkane, L., Roudaut, G., Saurel, R. Encapsulation and oxidative stability of PUFA rich oil microencapsulated by spray drying using pea protein and pectin. Food and Bioprocess Technology. 2014, 7(5), 1505-1517.

[9] Tonon R. V., Grosso, C. R. F., Hubinger, M. D. Influence of emulsion composition and inlet air temperature on the microencapsulation of flaxseed oil by spray drying. Food Research International. 2011, 44(1), 282-289.

[10] Aghbashlo, M., Mobli, H., Madadlou, A. \& Rafiee, S. The correlation of wall material composition with flow characteristics and encapsulation behavior of fish oil emulsion. Food Research International. 2012, 49(1), 379-388.

[11] Gallardo, G., Guida, L., Martinez, V., Lopez, M. C., Bernhardt, D., Blasco, R., Pedroza-Islas , R., \& Hermida, L. G. Microencapsulation of linseed oil by spray drying for functional food application. Food Research International. 2013, 52(2), 473-482.

[12] AOAC International, Official analytical methods of AOAC International. MD, USA: Gaithersburg. 1984.

[13] Bae, E. K., \& Lee, S. J. Microencapsulation of avocado oil by spray drying using whey protein and maltodextrin. Journal of Microencapsulation. 2008, 25(8), 549-560.

[14] ISO 3976/IDF 74. Milk fat - Determination of peroxide value. (second edition). 2006.

[15] Partanen, R., Raula, J., Seppänen, R., Buchert, J., Kauppinen, E. and Forssell, P. Effect of relative humidity on oxidation of flaxseed oil in spray dried whey protein emulsions. Journal of Agricultural and Food Chemistry. 2008, 56(14), 5717-5722.

[16] Goula, A. M., Adamopoulos, K. G. \& Kazakis, N. A. Influence of spray drying conditions on tomato powder properties. Drying Technology. 2004, 22, 1129-1151.

[17] Muzaffar, K., Kumar, P. Parameter optimization for spray drying of tamarind pulp using response surface methodology, Powder technology. 2015, 279, 179-184.

[18] Bhandari, B. R., Dumoulin, E. D., Richard, H. M. J., Noleau, I., Lebert, A. M. Flavor encapsulation by spray drying - application to citral and linalyl acetate. Journal of Food Science, 1992, 57(1), 217-221.

[19] Seddighi pashaki, A., Emam-djomeh, Z., Askari, G. Evaluation of spray drying parameters on physicochemical properties of seedless black Barberry (Berberis Vulgaris L.) juice. 20th International Drying Symposium. 2016, Japan. 